\title{
Reply to Mark Elvin
}

was quite pleased to learn that a respected scholar of Chinese history, Mark Elvin, had written a review essay of my book The Uniqueness of Western Civilization (2011). Elvin's estimation is that Uniqueness is "an alpha-delta book - with some very good and some unnervingly bad components." He sees a "fundamental cleavage" between those who explain the rise of the West in terms of some deep-seated quality in Europe's culture going back to ancient times, and those who stress "conjunctural" developments, "numerous historical currents of significantly different characters," and "relatively short-lived but world-transforming" episodes. The manner in which Elvin words these two approaches suggests that his sympathies are closer to the latter; though he would have us believe that he is a reasonable and fair-minded judge. Having read and cited some of Elvin's work, I would say that his intellectual frame is socialistic, materialistic, secular, and multiculturalist.

All of us have cultural biases, so let me concede that I prefer the West to any other civilization. At the same time, my book cites over 850 different sources in its effort to demonstrate the uniqueness and superiority of the West. This is not a task much welcomed in our current academic establishment, where students are regularly taught that "diverse" cultures are pretty much equal in value. In this world, writing that the West is superior is deemed "extremist" - apart from the evidence. Elvin refers to those on the "Eurocentric" side of this debate as "the uncompromisingly pro-European cultural extremists," whereas he distinguishes "the extreme proponents of the other [revisionist] perspective" from the more reasonable, and liberal-minded proponents (like him).

Elvin calls one of my arguments "dangerous." After a meager sentence on the "alpha" side of the book - "Duchesne probably wins most of his case on economic issues relating to the comparison between Europe and China, even if only narrowly" — he dedicates the entire review to the "delta" components. I will reply seriatim to his main criticisms:

1. Elvin challenges all my central arguments explaining how and why the West was unique, yet he barely cites any words from what is a $500+$ page book. Of the nine occasions in which he cites short phrases or one-line sentences, five come from the two-page Preface. The five sentences from the Preface are the basis of his most critical remarks, which consist in large measure of words taken (sometimes verbatim) from his earlier publications, i.e., a chapter in Hans Ul- 
rich and Gunter Dux (2010), a chapter in Carrithers, Collins and Lukes (1985), and a "Comment" in Bernholz and Vaubel (2004). It is almost as if Elvin had already formulated a refutation of my book years before it was published!

2. I never argued that anthropology was inherently flawed as a discipline per se. I explicitly praised as uniquely Western the anthropological idea that all cultures should be studied from a "universal" (or less Eurocentric perspective) with "equal respect and liberalmindedness." I criticized anthropologists for attacking the Western Enlightenment as "ethnocentric," in that they don't even pause to reflect on the fact that their own discipline is Western. I asked, for example: "Is not the emphasis on cultural pluralism a form of universalism that requires modes of reflective reasoning (metacultural, historical, and anthropological) that are/were unavailable in other cultures and that threaten/have threatened the particular traditions and standards of diverse cultures?" (19-31, 32 ).

3. Elvin wonders whether I am "advocating creationist idealism" in criticizing evolutionary materialism. To the complete contrary, I dedicated two whole sections, "The Exclusion of Sociobiology," and "Progress and the State of Nature," to argue that the same evolutionary materialists who stress the material conditions of life (geography, biodiversity, technology, relations of production, etc.), have suppressed or ignored the findings of sociobiologists and Darwinian theorists, merely because they can't digest findings (hierarchical relations are deeply rooted in the nature of humans) that refute the egalitarian goals of the academic establishment.

4. Elvin relies on Lucio Russo's book, The Forgotten Revolution: How Science Was Born in 300 BC and Why It Had to Be Reborn (2004) to argue that "there have probably only been two periods when Europe ... was arguably distinctive," namely, during the Hellenistic period and the period associated with the rise of Modern science around 1600. Then he asks: what about "the vast hiatus" between these two periods? He wonders why I ignored the Hellenistic Revolution and the rise of modern science, and further asks whether it makes sense to speak of Western uniqueness in light of this "vast hiatus." During the medieval era science was "mostly conserved and created anew outside Europe."

Perhaps Elvin, if he had engaged arguments beyond the Preface, might have noticed the numerous elaborations throughout the book showing that "the West has always existed in a state of variance from the rest of the world's cultures." I did debate more than once 
the obvious role of modern science (pp. 108, 146-151, 172-203, 236-242, 249-250) against revisionists who have minimized it in their "extremist" contention that the West and Asia were "surprisingly similar" as late as 1800-30. But one of the central theses of my book is that the exceptionality of the West includes far more than the rise of modern science (or Hellenistic science, for that matter). The Greek discovery of logos, reasoned discourse and its link with the order of the world, the concept of natural law, the Greek invention of prose, tragedy, politics, and face-to-face infantry battle were already unique developments. The Roman creation of a secular system of governance anchored on autonomous principles of judicial reasoning was in and of itself a divergence. The fusion of Christianity and the Greco-Roman heritage, coupled with the cultivation of the first rational theology in history, Catholicism, was a unique phenomenon. Christianity was unlike any other religion in nourishing a theological outlook of God's nature, intentions, and demands consistent with the rational investigation of nature. The medieval invention of universities - in which a secular education could flourish and even articles of faith were open to criticism and rational analysis in an effort to arrive at the truth - was exceptional. The Reformation was no less significant in promoting such modern Western values as social reform, inner conviction, hard work, and the rejection of empty ritual. The French Revolution was radical in wiping out every surviving feudal relic and promulgating the "rights of man" in general and the democratic ideal of universal suffrage. So were the Renaissance, the military revolution(s), the Romantic revolt, the German philosophical revolution from Kant to Hegel to Nietzsche, and much more.

I distinctly argued that countless books have been published on one or two major European transformations, but that no scholar has tried to explain, or pose as a general question, the "continuous" creativity and revolutionary character of Europeans from ancient to modern times. The norm has been for specialists in one period or transformation to write about (or insist upon) the "radical" or "revolutionary" significance of the period or theme they happen to be experts on. Lucio Russo's emphasis on the importance of Hellenistic science follows this norm. I have no difficulty taking this book seriously since its argument reinforces my thesis - so long as we reject

i) the supposition that this "forgotten revolution" was the one that marked out the distinctiveness of the ancient West, and

ii) Elvin's claim that the Hellenistic era was followed by a "vast hiatus" that lasted until 1600 . 
Even if we were to reduce Western uniqueness to the development of science, the medieval era (never mind the early modern era before 1600) cannot be interpreted as a time when science developed "mostly" outside Europe. Medieval Europe is no longer seen as a "dark" continent by the foremost scholars. David Lindberg limits the heyday of Islamic creativity to the period between 800 and 1100 , and adds that by 1200 Europe had recovered much of the Greek scientific and philosophical legacies nurtured by the Muslims (1992; see also Lindberg and Numbers 1986). Toby Huff (1993) believes that, up until the 14th century, Arabic science remained "promising" and was sufficiently developed "as to be called the most advanced in the world." In the case of astronomy, the supremacy lasted until the mid-1500s, when Copernicus came. Huff adds that the cultural and institutional foundations of the rise of modern science in Europe were already set in place during the 12th and 13th centuries, that is, a distinctive legal system of canon law which led to the rise of whole new systems of law - urban law, merchant law, royal law, natural law, divine law - that served to create a civil society composed of kingdoms, bishoprics, urban communes, guilds, and universities each empowered to adjudicate its own affairs (see also Huff 2011). Edward Grant (1986, 2001), for his part, convincingly shows that medieval Europe was the first civilization to "institutionalize reason" within self-governing universities which offered a curriculum "overwhelmingly oriented toward analytical subjects: logic, science, mathematics, and natural philosophy." Alfred Crosby (1997) draws attention to an "epochal shift from qualitative to quantitative perception" starting in the 1200 s, leading to a new conception of time as a succession of quanta, and a new polyphonic music where sounds could be seen as a phenomena moving through time, written on a paper using a codified and standardized system of notation for all sounds and rests.

How can "hiatus" be the best word to describe the period from Hellenistic times to the rise of modern science, a period which includes as well the Renaissance, the Reformation, the Portuguese voyages of exploration, the Discovery of America, the Printing Revolution, the Military Revolution, and the Cartographic Revolution?

5. Elvin uses the term "Europe" liberally in his writings, as if aware that a place called "Europe" can be distinguished from other areas/ civilizations. But lacking a clear intellectual centre, and feeling much obliged to the pressures of "diversity," he questions the way I separate "a domain called Europe" from Africa and the Near East, on the grounds that "classical 'Africa' included Alexandria, home 
to some of the greatest Hellenistic scholars and scientists of the ancient world...."Well, the truth happens to be that every Hellenistic thinker in Alexandria was Greek. Besides, Elvin's allegation that I cut Europe off from the rest of the world ignores the many times, particularly in Chapter 4, where I openly acknowledged the contributions of Islam and Asia, while explaining why Europe was a civilization with its own distinctive identity and contributions. I explicitly wrote that we should move beyond the multicultural promotion of a "uniformly connected global village" and address the reality that "the regions of the world have not been connected in the same way and in the same degree throughout their histories." Europe was the most connected civilization both geographically and culturally. It was the most eager to learn from others and then cultivate its own innovations and ideas (pp. 58-61; 172-181).

6. Citing the Preface, yet again, Elvin goes on to reject my effort to show that "the great accomplishments in the sciences and arts were overwhelmingly European." It is not possible to "adjudicate" on the quality of the arts across cultures, he says. I agree, and said so in Chapter 6, in a section headed, "Measuring Human Accomplishments." I relied on Charles Murray's Human Accomplishment, Pursuit of Excellence in the Arts and Sciences, 800 BC to 1950, which is the first statistical book (664 pages) to quantify "as facts" the accomplishments of individuals and countries across the world, by calculating the amount of space allocated to these individuals in reference works, massive encyclopedias, and multivolume dictionaries (Murray uses a total of 183 such sources). I explained how Murray "avoids a Eurocentric bias by creating separate compilations for each of 'the giants' in the arts of the Arab world, China, India, and Japan, as well as of the 'giants' of Europe." In this respect, I went on to say: Murray recognizes that one cannot apply one uniform standard of excellence for the diverse artistic traditions of the world." Murray produces combined (worldwide) inventories of 'the giants' for each of the natural sciences on the grounds that "it is possible to create combined lists for the natural sciences insofar as scientists themselves have come to accept the same methods and categories" (p. 291).

I did argue that experts can (and always do) make judgments about the quality of the arts, but not across cultures. Actually, it is Elvin who then writes that Cao Xueqin A Dream of the Young Ladies' Apartment "is one of the four or five greatest novels ever written"!? By what criteria, assuming he has read them, does he adjudicate all the novels of the world to make this judgment? I may add that Cao 
Xueqin's Dream of the Red Chamber (to use the title of the translation I have) is known as one of only "Four Great Classical Novels" of Chinese literature. Many other tales were written, satirical, edifying, criminal, and sentimental stories, but today they are generally not seen as having the status of great books of the world. Strictly speaking, none of the Great Classical Novels were novels. The word "novel" came into use only at the end of the 18th century in England as a transliteration of the Italian word "novella." The roots of the novel can be traced back to

i) Spanish picaresque tales (1500s) with their strings of episodic adventures held together by the personality of the central figure;

ii) Elizabethan prose fiction and the translation of ancient Greek romances into the vernacular,

iii) French heroic romance (mid 17th century) with its huge baroque narratives about thinly veiled contemporaries who always acted nobly and spoke high-flown sentiments.

What British novelists added in the 1700s was a more unified and plausible (down-to-earth) plot structure, with sharply individualized and believable characters, and a less aristocratic (or more "middle class") style of writing. The novel, in these respects, was invented in Europe, particularly after 1750 (Watt 2001). It was "associated from its inception," in the words of Roy Porter, "with individualism and a certain political liberalism" (2000:283). England played the leading role in this genre, cultivating a new sensibility for authenticity, personal experience and feeling, a spirit of nonconformity towards rigid and "insincere" conventions, a fascination with the inner depths of the affective self. Samuel Richardson's Clarissa was one of such novels, as was Pamela and Sir Charles Grandison by the same author; as well as Sarah Fielding's The Adventures of David Simple (1744), Henry Brooke's The Fool of Quality (1765), Daniel Defoe's Robinson Crusoe (1719) and Moll Flanders (1722), Oliver Goldsmith's The Vicar of Wakefield (1764), Lawrence Sterne's Tristram Shandy (1759-67) and A Sentimental Journey (1767), and more popularly Charlotte Smith's Emmeline (1788), Ethelinde (1789), Celestina (1791), Desmond (1792), The Old Manor House (1793), The Wandering of Warwick (1794), The Banished Man (1794), Montalbert (1795), Marchmont (1796), and The Young Philosopher (1798).

7. Elvin questions my arguments on accomplishments in the sciences, but then arbitrarily decides to include "technology" in his counterassessment, to argue that my view "as applied to the world before 
about 1600 is dangerous [sic] and potentially misleading exaggeration." But why include technology in an argument about the theoretical sciences, and, worse yet, why presume that I ignored the obvious technological feats of China? I discussed Chinese technology and economic development throughout Chapters 2, 3, and 4, including the writings of Weber and Needham on China (pp. 171-76; 249-254). I recognized the achievements of Chinese applied science "particularly in the period before 1500," but agreed with Needham that Chinese science remained too practical (too technological) in its "orientation and did not formulate a theoretical outlook which assumed a rational, orderly universe guided by universal laws" (p. 250). I stand by Murray's conclusion, as cited in my book (p. 292), that "whether measured in people or events, 97 percent of accomplishment in the sciences occurred in Europe and North America" from $800 \mathrm{BC}$ to 1950 - until I see scholarly evidence to the contrary, rather than wishful multicultural thinking.

8. Elvin calls "original" my thesis on the aristocratic Indo-European roots of Western creativity but "suspects many readers will find it outrageous." This thesis is detailed in Chapter 7 and most of Chapter 8 , covering about 150 pages and backed by hundreds of sources. Elvin cites, yet again, a line from the Preface, and then dismisses the argument with a few lines of his own. I am confident that welleducated readers will find the thesis rather persuasive, or this is the sense I am getting from what I know, thus far, about five upcoming review essays. Elvin wonders about India's Indo-European background. If he had read the respective chapters he might have noted that I tackled this question in two sections, "The Distinctive IndoEuropeanization of the West," and "Impact of Indo-Europeans of the Civilizations of the East." Elvin wonders as well about other warlike peoples from the steppes such as the Mongols and Turks. I mentioned non-Indo-European groups from the steppes but indicated this would be a matter of future research. Recently, I read Christopher Beckwith's book, Empires of the Silk Road: A History of Central Eurasia from the Bronze Age to the Present, which came out in 2009 as I was writing my book. It brings up some pertinent issues, including an emphasis on the crucial institution called comitatus, a war band of aristocratic warriors driven by heroic ideals. Beckwith sees these war bands throughout the steppes, rather than exclusively among Indo-European speakers. Yet, all in all, what he says solidifies my thesis. He agrees that the comitatus "goes all the way back to the Proto-Indo-European times"; and shows that the Ural-Altaic steppe peoples evolved, as I suggested, in a direction much more in- 
fluenced by the Asian peripheral civilizations. This has been further corroborated by my readings of Carter Findley's The Turks (2005), and David Morgan's The Mongols (1984). It should not be forgotten, moreover, that it was the Proto-Indo-Europeans who originated and developed the steppe toolkit, horse riding, wheel vehicles, chariots, and the "secondary-products revolution." My book avoids a teleological reading of the aristocratic culture of Indo-Europeans by showing that their contributions were only "the beginning" of multiple cultural developments in varying geographical and cultural settings.

9. Elvin next questions my argument that The Epic of Gilgamesh was not a heroic tragedy like the Iliad or Beowulf. He says that my "dismissal of the deep similarities" of these works "overlooks some recent work." By "recent" he means Andrew George's 1999 translation of The Epic of Gilgamesh. For the record, in the section "The Epic of Gilgamesh is not a Heroic Tragedy," I relied on 24 cited sources. I used the 1981 Penguin Edition of The Epic of Gilgamesh, translated by N. Sanders. I also used a long review essay by Jasper Griffin (2006) of Stephen Mitchell's Gilgamesh: A New English Version. The suggestion that I dismissed scholars who have argued for deep similarities between these epics is nothing short of absurd. First, Griffin and Sanders (in his introduction to his 1981 translation) are both of the view that these tragedies are similar, and I debated them respectfully; and, second, I took on the works of the two foremost scholars who have argued for similarities, M.L. West and Walter Burkert. Their works are "recent." Elvin's claim that I am "adamantly opposed to any parallels" between these epics is also ludicrous. I took on and recognized some of the parallels but explained why these common elements were rather superficial and do not warrant calling Gilgamesh a heroic tragedy.

The one other "recent" source Elvin employs against my argument is Speiser's 1958 translation of the Akkadian version of Gilgamesh. He cites the phrase "the most splendid among heroes," as if this little phrase demonstrates that this epic is as heroic as the Iliad and Beowulf. The segment of the poem this phrase is taken from reads:

'Who is the most splendid among the heroes? [Gilgamesh asks the people of Uruk] Who is most glorious among men?' 'Gilgamesh is most splendid among the heroes. Gilgamesh is most glorious among men'

Clearly, anyone who read this section in Uniqueness will have realized that my argument was that Gilgamesh should not be considered 
a heroic epic precisely because only Gilgamesh, the one ruler, is called heroic. Heroism, as I define it, presupposes the existence of peers who can compete for heroic status. Agamemnon in the Iliad, for example, is surrounded by free, prideful aristocrats always deliberating and competing with their peers. Agamemnon is "first among equals"; Achilles even refuses to accept all of his commands, and everyone else in the epic enjoys the opportunity to perform glorious deeds. In all the epics and sagas of the Western world we meet individually named characters, rather than one singular ruler bragging endlessly and demanding adoration from servile populations. Elvin has a rather smug attitude here suggesting that all he needs to do is offer a few more passages from Gilgamesh and my "argument for uniqueness crumbles."

10. Elvin questions my argument that "the emergence of the self" was a distinctively western phenomenon. Again, rather than engaging the book, he simply refers to a chapter he wrote in Carrithers, Collins, and Lukes (1985) on "conceptions of the self in China." I read this chapter and none of what it says challenges the detailed arguments I offered using Hegel, Nietzsche, Kojeve, Plato, Charles Taylor, Clifford Geertz, and numerous specialized sources. What Elvin says about the "self" in China is consistent with my qualifying statement that, on a basic level, humans at all times and places have had a sense that there is a person ' $A$ ' and a person ' $B$ ' to whom different physical attributes, actions, and momentary expressions can be attributed (p. 432). Elvin himself is forced to acknowledge that the self in modern Chinese thought (whatever there was of it) was eventually almost extinguished and absorbed "into a collective consciousness" (1985:174). Instead of consulting a chapter he wrote over 25 years ago, Elvin might offered readers a more interesting take on this question alerting us to David Hall and Roger Ames's book Thinking from the Han: Self, Truth and Transcendence in Chinese and Western Culture (1998). This book argues that the qualities of "self" and "person" as known in the West are not present in Chinese civilization. This book, I might add, traces the Western concept of "self" back to the agonistic heroic culture of Homeric times, and points out that Hegel's philosophy "rehearsed in the most complete form the means of coming to cultural self-consciousness" (1998:12).

Multiculturalism is an effort to destroy the uniqueness of Western nations. My book hopes to encourage Westerners to recover and affirm their exceptional historical identity.

University of New Brunswick, Saint John Ricardo Duchesne 


\section{REFERENCES}

Crosby, Alfred. 1997. Measure of Reality: Quantification and Western Society, 1250-1600. Cambridge: Cambridge University Press.

Elvin, Mark. 2004. Comment. In Peter Bernholz, and Roland Vaubel, Political Competition, Innovation and Growth in the History of Asian Civilizations. Cheltenham, UK: Edward Elgar Publishing.

Grant, Edward. 1996. The Foundations of Modern Science in the Middle Ages: Their Religious, Institutional and Intellectual Contexts. Cambridge: Cambridge University Press.

2001. God \& Reason in the Middle Ages. Cambridge: Cambridge University Press.

Griffin, Jasper. 2006. The true epic vision. New York Review of Books, LIII (4).

Huff, Toby. 2003. The Rise of Early Modern Science, Islam, China, and the West. Cambridge: Cambridge University Press.

2011. Intellectual Curiosity and the Scientific Revolution, A Global Perspective. Cambridge: Cambridge University Press.

Lindberg, David. 1992. The Beginnings of Western Science: The European Scientific Tradition in Philosophical, Religious, and Institutional Context, Prehistory to A.D. 1450 Chicago: University of Chicago Press.

Lindberg, David, and Ronald L. Numbers. 1986. God and Nature: Historical Essays on the Encounter between Christianity and Science. Berkeley: University of California Press.

Porter, Roy. 2000. Enlightenment, Britain and the Creation of the Modern. London: Penguin Books.

Watt, Ian. 2001. The Rise of the Novel. Berkeley: University of California Press. 